\title{
Additive effect of 5-HT2C and CB1 receptor blockade on the regulation of sleep-wake cycle
}

\author{
Emese Bogáthy ${ }^{1}$ (B), Noémi Papp ${ }^{1}$, Laszló Tóthfalusi' ${ }^{1}$ Szilvia Vas ${ }^{1,2,5}$ and György Bagdy ${ }^{1,2,3,4^{*}}$
}

\begin{abstract}
Background: Previous data show that serotonin $2 \mathrm{C}\left(5-\mathrm{HT}_{2} \mathrm{C}\right)$ and cannabinoid $1\left(\mathrm{CB}_{1}\right)$ receptors have a role in the modulation of sleep-wake cycle. Namely, antagonists on these receptors promoted wakefulness and inhibited rapid eye movement sleep (REMS) in rodents. The interaction of these receptors are also present in other physiological functions, such as the regulation of appetite. Blockade of $5-\mathrm{HT}_{2}$ receptors modulat the effect of $\mathrm{CB}_{1}$ receptor antagonist, presumably in consecutive or interdependent steps. Here we investigate, whether previous blockade of $5-\mathrm{HT}_{2 \mathrm{C}}$ receptors can affect $\mathrm{CB}_{1}$ receptor functions in the sleep-wake regulation.

Results: Wistar rats were equipped with electroencephalography (EEG) and electromyography (EMG) electrodes. Following the recovery and habituation after surgery, animals were injected intraperitoneally (ip.) with SB-242084, a $5-\mathrm{HT}_{2 \mathrm{C}}$ receptor antagonist $(1.0 \mathrm{mg} / \mathrm{kg}$ ) at light onset (beginning of passive phase) followed by an injection with AM-251, a CB 1 receptor antagonist (5.0 or $10.0 \mathrm{mg} / \mathrm{kg}$, ip.) $10 \mathrm{~min}$ later. EEG, EMG and motor activity were analyzed for the subsequent $2 \mathrm{~h}$. Both SB-242084 and AM-251 increased the time spent in active wakefulness, while decreased the time spent in non-REMS and REMS stages in the first $2 \mathrm{~h}$ of passive phase. In combination, the effect of the agents were additive, furthermore, statistical analysis did not show any interaction between the effects of these drugs in the modulation of vigilance stages.
\end{abstract}

Conclusions: Our results suggest that $5-\mathrm{HT}_{2}$ receptor blockade followed by blockade of $\mathrm{CB}_{1}$ receptors evoked additive effect on the regulation of sleep-wake pattern.

Keywords: Serotonin 2C receptor, SB-242084, Cannabinoid 1 receptor, AM-251, Sleep, Electroencephalography

\section{Background}

The serotonin (5-HT) and the endocannabinoid (eCB) systems show clear interaction in the regulation of various physiological functions, like anxiety and depression [1-3], coping with stress [4], fear extinction [5] and in the regulation of appetite [6, 7]. The 5-HT system has a well-known role in the sleep-wake regulation as well. Serotonergic neurons fire most actively during wakefulness, decrease their activity rate during non rapid eye movement sleep (non-REMS) and fall silent during rapid eye movement sleep (REMS) [8]. Several data support that the eCBs and the cannabinoid $1\left(\mathrm{CB}_{1}\right)$ receptors also affect the circadian rhythmicity and the sleep-wake

\footnotetext{
*Correspondence: bag13638@iif.hu

${ }^{1}$ Department of Pharmacodynamics, Semmelweis University, Budapest, Nagyvárad tér 4, 1089, Hungary

Full list of author information is available at the end of the article
}

cycle. The eCBs might participate in the sleep promotion by increasing the time spent in non-REMS and REMS, while reducing wakefulness [9]. At the same time, considering the connection between the 5-HT and the eCB systems in the sleep-wake regulation, only a few studies can be found in the literature. The increase in the time spent in slow wave sleep (SWS) by oleamide (a cannabimimetic molecule) was prevented by 5 -HT reuptake inhibitors such as fluoxetine or fenfluramine, but also by agonists of the $5-\mathrm{HT}_{1 \mathrm{~A}}$ receptors [10]. Oleamide has also been reported to potentiate the action of $5-\mathrm{HT}$ on $5-\mathrm{HT}_{2 \mathrm{C}}$ receptors expressed by Xenopus oocytes [11].

The $5-\mathrm{HT}_{2 \mathrm{C}}$ and $\mathrm{CB}_{1}$ receptors are widely distributed in sleep-modulating areas of the brain, frequently located on local inhibitory gamma-aminobutyric acidergic (GABAergic) interneurons and glutamatergic neurons [12-15]. The GABA release, caused by the activation of $5-\mathrm{HT}_{2 \mathrm{C}}$ receptors consequently evokes inhibitory effect 
on monoaminergic cell groups $[13,16]$. Accordingly, the role of $5-\mathrm{HT}_{2 \mathrm{C}}$ receptors has been demonstrated in the sleep-wake regulation as well. Administration of the 5- $\mathrm{HT}_{2 \mathrm{C}}$ agonists, $\mathrm{RO}$ 60-0175 and RO 60-0332 increased wakefulness and decreased REMS [17]. In line with this, mice lacking $5-\mathrm{HT}_{2 \mathrm{C}}$ receptors had greater amounts of wakefulness and spent significantly less time in nonREMS compared to wild-type controls [18]. Injections of ritanserin and ketanserin, possessing $5-\mathrm{HT}_{2 \mathrm{~A} / 2 \mathrm{C}}$ receptor antagonist properties, induced a significant increase in SWS and a reduction of both REMS and wakefulness in rats [19-23]. However, our previous data show that SB-242084, a highly selective $5-\mathrm{HT}_{2 \mathrm{C}}$ receptor antagonist, promotes wakefulness while decreases both deep slow wave sleep (SWS-2) and REMS [24, 25].

The role of eCBs in the promotion and maintenance of sleep have also been supported by genetic studies, namely $\mathrm{CB}_{1}$ receptor knockout mice spent more time in wakefulness compared to their wild-type littermates [26, 27]. The $\mathrm{CB}_{1}$ receptor antagonists SR141716a (rimonabant) and AM-251 have been reported to increase wakefulness, reduce both non-REMS and REMS in monotherapy [28, 29], moreover, could block sleep-wake alterations caused by eCBs [30].

Exploration of the eCB system is still in the focus of research. Up-regulation of the $\mathrm{eCB}$ system has been found in various disorders like obesity, metabolic disorder, osteoporosis, hyperalgesia, intestinal inflammation, and in certain cases of impaired fertility in women [14]. Thus, investigating the effects of $\mathrm{CB}_{1}$ receptor blockade and its interaction with another neurochemical pathways may open a way for new therapeutic application of these drugs.

In behavioral studies, more specific interactions have been described between the $\mathrm{CB}_{1}$ and $5-\mathrm{HT}_{2 \mathrm{C}}$ receptors. Soria-Gomez et al. [31] have shown that hypophagia induced by oleamide and AM-251 has been blocked by SB-242084. Based on the above mentioned findings, we aimed to investigate how previous $5-\mathrm{HT}_{2 \mathrm{C}}$ receptor blockade modifies the effect of a $\mathrm{CB}_{1}$ receptor antagonist on the pattern of sleep-wake cycle.

\section{Methods}

\section{Animal maintenance}

All animal experiments and housing conditions were carried out in accordance with the EU Directive 2010/63/ EU and the National Institutes of Health "Principles of Laboratory Animal Care" (NIH Publications No. 85-23, revised 1985), as well as specific national laws (the Hungarian Governmental Regulations on animal studies 40/2013). The experiments were approved by the National Scientific Ethical Committee on Animal Experimentation. Male, drug and test naïve Wistar rats were purchased from Animal Facility (Semmelweis University, Budapest, Hungary). Rats (8 weeks old), weighing 300$330 \mathrm{~g}$ at surgery, were kept under controlled environmental conditions (temperature at $21 \pm 1{ }^{\circ} \mathrm{C}$ and a $12 \mathrm{~h}$ light-dark cycle starting at 10:00 A.M.). Rats were kept three per cage before surgery. Food and water were available ad libitum during the whole experiment. All efforts were made to minimize pain and suffering of the rats. Rats were euthanized with an overdose of anesthetic (halothane) when the experimental procedure was finished.

\section{Surgery}

Rats were chronically equipped with electroencephalographic (EEG) and electromyographic (EMG) electrodes, as described earlier [32]. Briefly, stainless steel screw electrodes were implanted epidurally over the left frontal cortex (2.0 mm lateral and 2.0 anterior $\mathrm{mm}$ to bregma) and left parietal cortex $(2.0 \mathrm{~mm}$ lateral and 2.0 anterior $\mathrm{mm}$ to lambda) for frontoparietal EEG recordings. The ground electrode was placed over the cerebellum. EMG electrodes (stainless steel spring electrodes embedded in silicon rubber; Plastics One Inc., Roanoke, VA, USA) were placed into muscles of the neck. Surgery was performed under halothane (2\%) anaesthesia (Fluotec 3 vaporizer) using a Kopf stereotaxic instrument.

\section{Drug administration}

SB-242084 [SB, 6-chloro-5-methyl-1-[2-(2-methylpyrid3-yloxy)-pyrid-5-yl carbamoyl] indoline] and AM-251 [AM, N-(Piperidin-1-yl)-5-(4-iodophenyl)-1-(2,4dichlorophenyl)-4-methyl-1H-pyrazole-3-carboxamide] were purchased from Tocris Cookson (Bristol, UK). Both compounds were dissolved in vehicle (veh) consisted of 70\% PBS (phosphate buffered saline, $\mathrm{pH}=7.4$ ), $20 \%$ dimethylsulfoxide and $10 \%$ Tween 80 . All rats were treated with a first (veh or $1 \mathrm{mg} / \mathrm{kg} \mathrm{SB}$ ) and a second [veh or $5 \mathrm{mg} / \mathrm{kg} \mathrm{AM} \mathrm{(AM} \mathrm{D5)} \mathrm{or} 10 \mathrm{mg} / \mathrm{kg}$ AM (AM D10)] intraperitoneal (ip.) injections in $1 \mathrm{ml} / \mathrm{kg}$ volume, with 10 min difference between the injections. Animals $(n=6)$ were treated with the following treatments, in crossover design: veh + veh, veh $+A M$ D5, veh $+A M$ D10, $\mathrm{SB}+$ veh, SB + AM D5, SB + AM D10.

\section{EEG recording}

After surgery, rats were kept in a square, glass recording chamber separately. After a 7-day-long recovery period, rats were attached to the EEG system by a flexible recording cable and an electric swivel, fixed above the cages, permitting free movement of the animals. In order to habituate the animals to the recording conditions, rats were attached to the EEG system 7 days before starting the treatments, and were kept connected to the system during the whole experiment. 
To assess motor activity, electromagnetic transducers were used, in which potentials were generated by movements of the recording cable, as described earlier [32]. EEG, EMG and motility were recorded during a 24-h long period, starting at light onset (10:00 A.M.). Rats were undisturbed throughout the recordings and had free access to standard rodent chow and tap water. The signals were amplified (amplification factors approximately 5000 for EEG and motor activity, 20000 for EMG), conditioned by analogue filters (Coulburn Lablinc System, USA; filtering below $0.50 \mathrm{~Hz}$ and above $100 \mathrm{~Hz}$ at $6 \mathrm{~dB}$ /octave), and subjected to analogue to digital conversion with a sampling rate of $256 \mathrm{~Hz}$. Data were stored on a computer for further analysis.

\section{Sleep scoring}

The vigilance stages were classified automatically by SleepSign for Animal sleep analysis software (Kissei Comtec America, Inc., USA) followed by visual assessment for 4-s periods over $2 \mathrm{~h}$, as described earlier [32]. The visual assessment and scoring were performed by an observer blind to the treatments. The vigilance stages scored in the present study were the following: active wakefulness (AW), the EEG is characterized by low-amplitude activity at beta $(14-30 \mathrm{~Hz})$ and alpha $(8-13 \mathrm{~Hz})$ frequencies accompanied by high EMG and intense motor activity; passive wakefulness (PW), the EEG is characterized by low-amplitude activity at beta $(14-30 \mathrm{~Hz})$ and alpha $(8-13 \mathrm{~Hz})$ frequencies accompanied by high EMG activity but minimal or no motor activity; light slow wave sleep (SWS-1), high-voltage slow cortical waves $(0.5-4 \mathrm{~Hz})$ were interrupted by spindles $(6-15 \mathrm{~Hz})$ accompanied by reduced EMG and no motor activity; deep slow wave sleep (SWS-2), there were continuous high-amplitude slow cortical waves $(0.5-4 \mathrm{~Hz})$ with reduced EMG and no motor activity; intermediate stage of sleep (IS), a brief stage just prior to REMS and sometimes just after it, characterized by unusual association of high-amplitude spindles (mean $12.5 \mathrm{~Hz}$ ) and low-frequency (mean $5.4 \mathrm{~Hz}$ ) theta rhythm; rapid eye movement sleep (REMS), low-amplitude and high-frequency EEG activity with regular theta waves $(5-9 \mathrm{~Hz})$ were accompanied by silent EMG and motor activity with occasional twitching. SWS-1 and SWS-2 sleep stages together create the non-REMS stage. The following parameters were calculated (1-2 $\mathrm{h}$ following treatments): total time spent in each vigilance stage (AW, PW, SWS-1, SWS-2, REMS, IS); the occurrence of the first REMS period (REMS latency). An episode of any vigilance stage was defined as an item lasting at least $4 \mathrm{~s}$ and not interrupted by any other vigilance stage for longer than $4 \mathrm{~s}$.

\section{Statistical analysis}

For statistical analysis STATISTICA 7.0 (Statsoft Inc., Tulsa, OK, USA) software was used. Data were analyzed by two alternative statistical approaches, the conclusions were drawn based on these two methods. Sleep parameters of the treatment groups were evaluated by two-way analysis of variance (ANOVA) with two factors: pretreatment [veh or $\mathrm{SB}$ ] and treatment [veh or AM DX ( $\mathrm{X}=5$ or $10 \mathrm{mg} / \mathrm{kg}$ dose $)]$ and their interaction. We also performed one-way ANOVA tests in each vigilance stage including the 6 treatment groups. In case of significant main effects of the one-way ANOVA tests, the difference between the groups was investigated by Dunnett's post hoc analysis (indicated on the figures). In contrast to two-way ANOVA, the post hoc methods compare the means of groups, with the special case of Dunnett's test, that compare all treated groups to the control one. The two methods are complementary to each other. The two-way ANOVA method is more powerful but the Dunnett's method is based on fewer statistical assumptions. In both statistical tests $\mathrm{p}$ values less than $0.05(\mathrm{p}<0.05)$ were defined as statistically significant. Data on the figures are presented as mean \pm SEM.

\section{Results}

SB-242084 and AM-251 showed additive active wake-promoting effect

With regard to wakefulness, SB-242084 and AM-251 treatments showed additive effect to increase the time spent in AW. However, post hoc analysis did not reveal significant effect of SB or AM D5 in mono-treatments, compared to the veh + veh control group. The AW-promoting effects of the drugs were statistically significant when administered simultaneously. The effect of AM D10 was significant in mono-treatment and in combination with SB as well (Fig. 1a). Two-way ANOVA showed significant effect of both $\mathrm{SB}$ and AM D5 $\left(F_{1,20}=6.777 ; p=0.0170\right.$ and $F_{1,20}=5.482 ; p=0.0297$, respectively) on the time spent in AW, but we did not find interaction between the two agents. Regarding the combination of SB with the higher AM dose, two-way ANOVA showed a tendency of SB to increase AW, a significant effect of AM D10 $\left(F_{1,20}=3.002 ; p=0.0985\right.$ and $F_{1,20}=7.263 ; p=0.0139$, respectively) on the time spent in AW and a trend in the interaction effect $\left(F_{1,20}=3.025 ; p=0.0974\right)$.

Regarding PW, we did not find any significant effect of SB, AM D5 or AM D10, or their combination in post hoc analysis or with two-way ANOVA statistics (Fig. 1b). 

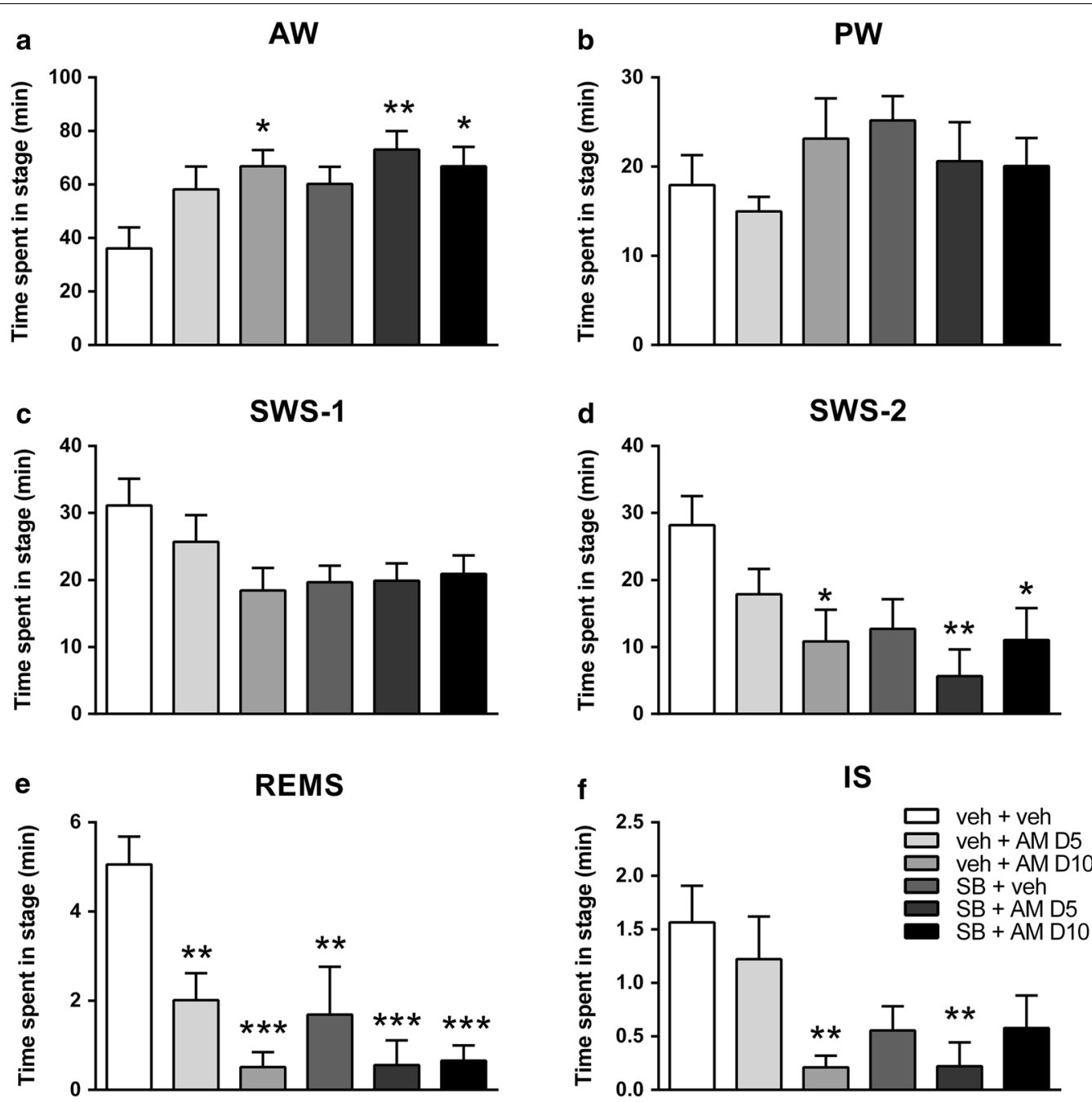

Fig. 1 The effects of SB-242084 (SB, 1 mg/kg ip.) and AM-251 (AM D5, 5 mg/kg ip. and AM D10, 10 mg/kg ip.) treatments on the time spent in a active wakefulness (AW); $\mathbf{b}$ passive wakefulness (PW); c light slow wave sleep (SWS-1); $\mathbf{d}$ deep slow wave sleep (SWS-2); e rapid eye movement sleep (REMS); $\mathbf{f}$ intermediate stage of sleep (IS) in the summarized first $2 \mathrm{~h}$ of the passive phase. Data are presented as mean \pm SEM of the 6 animals. ${ }^{*} p<0.05,{ }^{* *} p<0.01,{ }^{* * *} p<0.001$ compared to the veh + veh control group (Dunnett's post hoc comparison)

SB-242084 and AM-251 caused additive reduction in slow wave sleep

In SWS-2 stage, the post hoc analysis after significant one-way ANOVA showed a trend effect of SB $(p=0.0683)$, although AM D5 treatment did not cause any significant effect. However, AM D10 mono-treatment showed a significant decrease in the time spent in SWS-2 compared to the veh + veh group. At the same time, the combination of SB with AM D5 or AM D10 doses showed a significant decrease in time spent in SWS-2 in both cases. Interestingly, this effect seemed to be stronger in case of the SB+AM D5 combination (Fig. 1d). Two-way ANOVA statistics revealed a significant effect of both the pretreatment with SB
$\left(F_{1,20}=11.25 ; p=0.0032\right)$, and the treatment with AM D5 $\left(F_{1,20}=4.402 ; p=0.0488\right)$. However, we did not find any interaction between the treatments $\left(F_{1,20}=0.1509\right.$; $p=0.7018)$. AM D10 treatment also showed a trend effect $\left(F_{1,20}=4.305 ; p=0.0511\right)$ in two-way ANOVA, but no interaction was found between the SB and AM D10 treatments.

Regarding SWS-1, SB significantly decreased the time spent in this stage (pretreatment effect: $F_{1,20}=6.648$; $p=0.0179$ ), but we did not find any significant treatment effect of AM D5 or AM D10 (Fig. 1c).

Taken together, in monotherapy the time spent in SWS- 2 was decreased by SB, AM D5 and AM D10 as well, while the time spent in SWS-1 was reduced by SB 
only. In combination, $\mathrm{SB}$ and $\mathrm{AM}$ showed a significant decrese in SWS-2 by post hoc results, compared to control. Both AM D5 and AM D10 treatments were capable to increase the effect of SB, suggesting additive effect of the drugs on reducing SWS-2 only.

\section{SB-242084 and AM-251 suppressed REMS and IS}

Regarding the post hoc tests after significant one-way ANOVA, SB, AM D5 and AM D10 showed significant REMS-reducing effect in both mono-treatment and in combinations (Fig. 1e). According to two-way ANOVA, both SB and AM D5 treatments significantly decreased the time spent in REMS $\left(F_{1,20}=10.48 ; p=0.0041\right.$ and $F_{1,20}=7.868 ; p=0.0109$, respectively), but we did not find any interaction effect $\left(F_{1,20}=1.646 ; p=0.2141\right)$. Similarly, significant pretreatment and treatment effects were seen in two-way ANOVA, when combining SB with AM D10 $\left(F_{1,20}=5.866 ; p=0.0251\right.$ and $F_{1,20}=17.58 ; p=0.0004$, respectively) and an interaction effect $\left(F_{1,20}=6.964\right.$; $p=0.0157)$ as well.

Regarding REMS latency, two-way ANOVA revealed that, both $\mathrm{SB}$ and $\mathrm{AM}$ D5 treatment significantly increased REMS latency (SB effect: $F_{1,19}=12.35$; $p=0.0023$; AM effect: $F_{1,19}=9.045 ; p=0.0072$ ). At the same time, in the SB+AM D10 combination, two-way ANOVA showed a significant treatment effect of AM D10 $\left(F_{1,15}=6.265 ; p=0.0244\right)$, moreover, an interaction between the two agents $\left(F_{1,15}=9.732 ; p=0.0070\right)$.

Regarding the time spent in IS, post hoc tests after one-way ANOVA showed, that AM D10 reduced IS significantly compared to veh + veh control group, while AM D5 produced a similar reduction when combined with SB (Fig. 1f). Two-way ANOVA showed a significant effect of SB in combination with AM D5 $\left(F_{1,20}=10.82\right.$; $p=0.0037)$. However, in the $\mathrm{SB}+\mathrm{AM} \mathrm{D} 10$ combination, AM D10 showed significant effect alone and an interaction effect as well $\left(F_{1,20}=6.532 ; p=0.0188\right.$ and $F_{1,20}=6.975 ; p=0.0157$, respectively).

To sum up, both SB and AM in both doses tended to decrease REMS. However, while the effect of AM D5 seemed to be added to the REM-suppressing effect of SB, AM D10 could not produce this additive effect, despite decresing REMS alone. The cause of this can be that the maximal REMS-decreasing effect was already reached by AM D10 in mono-treatment, thus, further enhancement of this effect was not possible by the combined treatment.

\section{Discussion}

Our study confirms, in agreement with previous findings, that the combination of $5-\mathrm{HT}_{2 \mathrm{C}}$ and $\mathrm{CB}_{1}$ receptor antagonists increases wakefulness, while decreases the time spent in non-REMS and REMS stages as a result of an additive effect of the agents. Based on two-way ANOVA, both SB and AM influenced AW, SWS-2, REMS and IS parameters and SB modulates SWS-1 too. The effect of $\mathrm{AM}$ was different in D5 and D10 doses. In $10 \mathrm{mg} / \mathrm{kg}$ dose AM increased AW, and decreased the time spent in SWS-2, REMS and IS, however, when applied in $5 \mathrm{mg} / \mathrm{kg}$ it reduced REMS only. In combination with SB, the effect of AM D5 and D10 was similar, increasing the time spent in AW, while reducing SWS-2 and REMS. The additive effect of $\mathrm{SB}$ and $\mathrm{AM}$ was obvious in the $\mathrm{SB}+\mathrm{AM}$ D5 combination. However, based on interaction effects of the $\mathrm{SB}+\mathrm{AM}$ D10 combination in the time spent in AW and SWS- 2 parameters, the additive effect was weaker in this combination.

Neurochemical and electrophysiological studies have found that the role of 5-HT in the sleep-wake regulation is promoting wakefulness and inhibiting REMS [33, 34]. Regarding $5-\mathrm{HT}_{2 \mathrm{C}}$ receptors, their mRNA has been found in the cholinergic pedunculopontine and laterodorsal tegmental nuclei (PPT/LDT) [12]. These neurons fire most rapidly during wakefulness and REMS, and most slowly during non-REMS [35]. The $5-\mathrm{HT}_{2 \mathrm{C}}$ receptors have been found in the dorsal raphe nuclei (DRN) as well [13] and are expressed mainly by inhibitory GABAergic interneurons, but also by excitatory glutamatergic neurons [36]. The exact mechanism of the elevation of the amount of wakefulness and the suppression of both non-REMS and REMS caused by the blockade of $5-\mathrm{HT}_{2 \mathrm{C}}$ receptors is still unclear, but these effects may be partially mediated by the suppressed activity of GABAergic neurons in the DRN. This decrease in the inhibitory influence of DRN may lead to an increase in the monoaminergic cell firing, consequently inducing an inhibition on the PPT/LDT neurons.

The role of eCBs has also been demonstrated in the regulation of the sleep-wake cycle, based on the finding that these bioactive lipids reduced wakefulness and promoted non-REMS and REMS [9]. In line with this, the $\mathrm{CB}_{1}$ receptor antagonists SR141716a and AM-251 presented the opposite effects, promoting wakefulness and decreasing both non-REMS and REMS activity [28, 29]. Intracerebroventricular administration of the eCB anandamide (ANA) during the lights-on period caused diminution in wakefulness, while increased non-REMS and REMS in rats. This effect was more evident when ANA was injected directly into the PPT nucleus, and SR141716a prevented this effect [37, 38]. Experimental evidence indicates that the activation of the $\mathrm{CB}_{1}$ receptors promotes the release of acetylcholine $(\mathrm{ACh})$ in cortical and hippocampal areas [39]. Therefore, the blockade of $\mathrm{CB}_{1}$ receptors in local GABAergic and glutamatergic networks might influence the release of ACh in the PPT/ LDT and in the basal forebrain inducing wakefulness and reducing sleep. 
With regard to the regulation of REMS by cannabinoids, infusion of 2-arachidonoylglycerol (2-AG) into the lateral hypothalamus caused a massive increase of REMS, while AM-251 was able to block this effect [40]. In the hypothalamic regulation of the sleep-wake cycle, WIN 55,212-2, a potent $\mathrm{CB}_{1}$ receptor agonist has been shown to depolarize melanin-concentrating hormone $(\mathrm{MCH})$ neurons in the hypothalamus in vitro [41]. In line with this, 2-AG activates these neurons in vivo, thereby increasing REMS [42]. MCH neurons promote non-REMS and REMS, by showing their maximal firing rate during REMS, moderately firing during nonREMS, and being almost silent during wakefulness [43]. These findings suggest that eCBs also influence the hypothalamic regulation of sleep acting on $\mathrm{MCH}$ neurons. Correlation between the amount of REMS and neuronal (Fos) activation of the $\mathrm{MCH}$ neurons during rebound sleep after selective REMS deprivation has also been demonstrated by Kitka et al. [44]. In rats, SR141716a has also been shown to prevent REMS rebound following selective REMS deprivation [45].

In our study, SB with the lower dose of AM $(5 \mathrm{mg} / \mathrm{kg})$ caused a clear additive effect in AW, SWS- 2 and REMS parameters, but these effects were weaker when SB was combined with AM D10. This phenomenon may be due to various reason. Several findings suggested a dosedependent pharmacological effect of WIN55,212-2 on the $\mathrm{CB}_{1}$ receptors of inhibitory and excitatory neurons in the hippocampus of mice, namely the inhibitory synaptic transmission was more sensitive to the effect of cannabinoid receptor modulator, than the excitatory neurotransmission [46, 47]. Another potential reason can be, that, in terms of $\mathrm{CB}_{1} / \mathrm{CB}_{2}$ receptor selectivity, $\mathrm{AM}-251$ similarly to its structural analog SR141716a, is a $\mathrm{CB}_{1}$ receptor selective compound in nanomolar concentration, but in higher doses the effect is not $\mathrm{CB}_{1}$ specific. Binding experiments showed, that in micromolar concentration, SR141716a and AM-251 can interact on both transient receptor potential vanilloid type 1 and adenosine A1 receptors [48-51]. Thus, the effect of the higher dose of AM-251 on other cell types or receptors might explains, why this dose attenuated the additive effect. In line with our findings, there is another example in the literature, where synergistic or additive effects of $\mathrm{CB}_{1}$ and $5-\mathrm{HT}_{2 \mathrm{C}}$ receptor functions showed dependency on the doseratios of the applied drugs. Ward et al. have measured the effect of SR141716a, meta-chlorophenylpiperazine (mCPP, a $5-\mathrm{HT}_{2 \mathrm{C}}$ receptor agonist) and their combination on motivation to consume a palatable drink in mice. When combined in 1:1 and 2:1 dose ratios, SR and $\mathrm{mCPP}$ produced significant synergistic effect, while in 3:1 ratio their interaction led to additive effect in attenuation of motivation to consume palatable drink [6].
Although, the additive effect of SB treatment with the higher dose of AM $(10 \mathrm{mg} / \mathrm{kg})$ was weaker, AM D10, similarly to AM D5 exerted its effect after SB-242084 treatment as well. Therefore, we can conclude that although the two drugs can produce additive interaction in a given dose, they might also act independently from each other. This is in agreement with literature data (see above) reporting that both SB and AM evoke their sleep-wake modulating effect by influencing $\mathrm{PPT} / \mathrm{LDT}$ neurons, however, can also exert their effect on different ways. SB modulates DRN neurons in the brainstem leading to the inhibition of PPT/LDT neurons firing, whereas AM influences local GABAergic and glutamatergic networks within the PPT/LDT exerting a more direct effect on these neurons. Luppi et al. [52] have also emphasized the role of local GABAergic and glutamatergic networks over the aminergic-cholinerg projections in REMS regulation. AM modulates the hypothalamic $\mathrm{MCH}$ neurons as well, but until nowadays no data is available investigating the effect of SB on this neuron population. Thus, the $\mathrm{MCH}$ neuron population might be the other target on which $A M$ can exert its effect independently from SB treatment.

\section{Conclusion}

Taken together, blockade of the $5-\mathrm{HT}_{2 \mathrm{C}}$ and $\mathrm{CB}_{1}$ receptors influences the sleep-wake pattern in a similar way by inducing wakefulness and suppressing both nonREMS and REMS. Our findings reinforce the role of $\mathrm{eCB}$ and serotonergic system in the regulation of sleep-wake behavior. These data also suggest that $5-\mathrm{HT}_{2 \mathrm{C}}$ receptor blockade followed by blockade of $\mathrm{CB}_{1}$ receptors evoke additive effects on the regulation of sleep-wake pattern that may provide additional information regarding their interaction in the central nervous system.

As the drugs were administered intraperitoneally, and not into specific nuclei of the brain involved in regulation of vigilance, we cannot exclude the influence of several other factors on their interaction in the regulation of sleep-wake cycle.

\footnotetext{
Abbreviations

2-AG: 2-arachidonoylglycerol; 5-HT: serotonin; 5- $\mathrm{HT}_{1 \mathrm{~A}}$ receptor: serotonin $1 \mathrm{~A}$ receptor; 5-HT 2 receptor: serotonin $2 \mathrm{C}$ receptor; $\mathrm{ACh}$ : acetylcholine; $\mathrm{AM}$ D10: $10 \mathrm{mg} / \mathrm{kg}$ dose of AM-251; AM D5: 5 mg/kg dose of AM-251; AM: AM-251; ANA: anandamide; $A W$ : active wakefulness; $C B_{1}$ receptor: cannabinoid 1 receptor; DRN: dorsal raphe nuclei; eCB: endocannabinoid; EEG: electroencephalography; EMG: electromyography; GABAergic: gamma-aminobutyric acidergic; ip.: intraperitoneally; IS: intermediate stage of sleep; MCH: melaninconcentrating hormone; mCPP: meta-chlorophenylpiperazine; non-REMS: non rapid eye movement sleep; PPT/LDT: pedunculopontine and laterodorsal tegmental nuclei; PW: passive wakefulness; REMS: rapid eye movement sleep;
} 
SB: SB-242084; SWS: slow wave sleep; SWS-1: light slow wave sleep; SWS-2: deep slow wave sleep.

\section{Authors' contributions}

$E B, S z V$ and $G B$ designed the experiments. EB and SzV carried out the experiments. EB, NP and LT contributed to data analysis. EB, SzV and GB interpreted the findings and wrote the final version of the manuscript. All authors read and approved the final manuscript.

\section{Author details \\ ${ }^{1}$ Department of Pharmacodynamics, Semmelweis University, Budapest, Nagyvárad tér 4, 1089, Hungary. ${ }^{2}$ MTA-SE, Neuropsychopharmacology and Neurochemistry Research Group, Budapest 1089, Hungary. ${ }^{3}$ NAP-A-SE, New Antidepressant Target Research Group, Budapest 1089, Hungary. ${ }^{4}$ NAP- 2-SE, New Antidepressant Target Research Group, Budapest 1089, Hungary. ${ }^{5}$ Department of Physiology, Development and Neuroscience, University of Cambridge, Cambridge CB2 3DY, UK.}

\section{Acknowledgements}

Support for this research was provided by the National Development Agency Hungarian Brain Research Program (Grant No. KTIA_13_NAP-A-II/14), by NAP 2.0 (Grant No. 2017-1.2.1-NKP-2017-00002) and by EFOP-3.6.3VEKOP-16-2017-00009 grant. We would like to thank to Ágnes Ruzsits for her excellent technical support.

\section{Competing interests}

The authors declare that they have no competing interests.

\section{Availability of data and materials}

The datasets generated and/or analyzed during the current study are not publicly available due to ongoing analysis for future publication, but are available from the corresponding author upon reasonable request.

\section{Consent for publication}

Not applicable.

\section{Ethics approval}

All animal experiments and housing conditions were carried out in accordance with the EU Directive 2010/63/EU and the National Institutes of Health "Principles of Laboratory Animal Care" (NIH Publications No. 85-23, revised 1985), as well as specific national laws (the Hungarian Governmental Regulations on animal studies 40/2013). The experiments were approved by the National Scientific Ethical Committee on Animal Experimentation and permitted by the government (Food Chain Safety and Animal Health Directorate of the Central Agricultural Office, Permit No. 22.1/1375/7/2010).

\section{Funding}

Support for this research was provided by the National Development Agency Hungarian Brain Research Program (Grant No. KTIA_13_NAP-A-II/14), by NAP 2.0 (Grant No. 2017-1.2.1-NKP-2017-00002) and by EFOP-3.6.3VEKOP-16-2017-00009 grant. The funders did not participate in the experimental research, or in the preparation the manuscript.

\section{Publisher's Note}

Springer Nature remains neutral with regard to jurisdictional claims in published maps and institutional affiliations.

Received: 3 December 2018 Accepted: 12 March 2019

Published online: 20 March 2019

\section{References}

1. Bambico FR, Duranti A, Nobrega JN, Gobbi G. The fatty acid amide hydrolase inhibitor URB597 modulates serotonin-dependent emotional behaviour, and serotonin $1 \mathrm{~A}$ and serotonin2A/C activity in the hippocampus. Eur Neuropsychopharmacol. 2016;26(3):578-90.

2. Umathe SN, Manna SSS, Jain NS. Involvement of endocannabinoids in antidepressant and anti-compulsive effect of fluoxetine in mice. Behav Brain Res. 2011;223(1):125-34
3. Burokas A, Martin-Garcia E, Gutierrez-Cuesta J, Rojas S, Herance JR, Gispert JD, Serra MA, Maldonado R. Relationships between serotonergic and cannabinoid system in depressive-like behavior: a PET study with [11C]-DASB. J Neurochem. 2014;130(1):126-35.

4. McLaughlin RJ, Hill MN, Bambico FR, Stuhr KL, Gobbi G, Hillard CJ, Gorzalka BB. Prefrontal cortical anandamide signaling coordinates coping responses to stress through a serotonergic pathway. Eur Neuropsychopharm. 2012;22(9):664-71.

5. Gunduz-Cinar O, Flynn S, Brockway E, Kaugars K, Baldi R, Ramikie TS, Cinar R, Kunos G, Patel S, Holmes A. Fluoxetine facilitates fear extinction through amygdala endocannabinoids. Neuropsychopharmacology. 2016:41(6):1598-609.

6. Ward SJ, Lefever TW, Jackson C, Tallarida RJ, Walker EA. Effects of a cannabinoid 1 receptor antagonist and serotonin $2 \mathrm{c}$ receptor agonist alone and in combination on motivation for palatable food: a dose-addition analysis study in mice. J Pharmacol Exp Ther. 2008;325(2):567-76.

7. Wierucka-Rybak M, Wolak M, Juszczak M, Drobnik J, Bojanowska E. The inhibitory effect of combination treatment with leptin and cannabinoid CB1 receptor agonist on food intake and body weight gain is mediated by serotonin 1B and 2C receptors. J Physiol Pharmacol. 2016;67(3):457-63.

8. Aston-Jones G, Bloom FE. Activity of norepinephrine-containing locus coeruleus neurons in behaving rats anticipates fluctuations in the sleepwaking cycle. J Neurosci. 1981;1(8):876-86.

9. Prospero-Garcia O, Amancio-Belmont O, Becerril Melendez AL, RuizContreras AE, Mendez-Diaz M. Endocannabinoids and sleep. Neurosci Biobehav Rev. 2016;71:671-9.

10. Yang JY, Wu CF, Wang F, Song HR, Pan WJ, Wang YL. The serotonergic system may be involved in the sleep-inducing action of oleamide in rats. N-S Arch Pharmacol. 2003;368(6):457-62.

11. Huidobro-Toro JP, Harris RA. Brain lipids that induce sleep are novel modulators of 5-hydroxytrypamine receptors. Proc Natl Acad Sci USA 1996;93(15):8078-82.

12. Clemett DA, Punhani T, Duxon MS, Blackburn TP, Fone KCF. Immunohistochemical localisation of the $5-\mathrm{HT} 2 \mathrm{C}$ receptor protein in the rat CNS. Neuropharmacology. 2000;39(1):123-32.

13. Serrats J, Mengod G, Cortés R. Expression of serotonin 5-HT2C receptors in GABAergic cells of the anterior raphe nuclei. J Chem Neuroanat. 2005:29(2):83-91.

14. Pertwee RG. Endocannabinoids and their pharmacological actions. Handb Exp Pharmacol. 2015;231:1-37.

15. Gocho Y, Sakai A, Yanagawa Y, Suzuki H, Saitow F. Electrophysiological and pharmacological properties of GABAergic cells in the dorsal raphe nucleus. J Physiol Sci. 2013;63(2):147-54.

16. Di Giovanni G, Di Matteo V, La Grutta V, Esposito E. m-Chlorophenylpiperazine excites non-dopaminergic neurons in the rat substantia nigra and ventral tegmental area by activating serotonin- $2 \mathrm{C}$ receptors. Neuroscience. 2001;103(1):111-6.

17. Martin JR, Bös M, Jenck F, Moreau J-L, Mutel V, Sleight AJ, Wichmann J, Andrews JS, Berendsen HHG, Broekkamp CLE, et al. 5- $\mathrm{HT}_{2}$ receptor agonists: pharmacological characteristics and therapeutic potential. J Pharmacol Exp Ther. 1998;286(2):913-24.

18. Frank MG, Stryker MP, Tecott LH. Sleep and sleep homeostasis in mice lacking the 5-HT2c receptor. Neuropsychopharmacology. 2002;27:869.

19. Kirov R, Moyanova S. Age-related effect of ritanserin on the sleep-waking phases in rats. Int J Neurosci. 1998;93(3-4):265-78.

20. Kirov R, Moyanova S. Age-dependent effect of ketanserin on the sleepwaking phases in rats. Int J Neurosci. 1998;93(3-4):257-64.

21. Dugovic C, Wauquier A. 5-HT2 receptors could be primarily involved in the regulation of slow-wave sleep in the rat. Eur J Pharmacol. 1987:137(1):145-6.

22. Dugovic C, Wauquier A, Leysen JE, Marrannes $R$, Janssen PA. Functional role of 5-HT2 receptors in the regulation of sleep and wakefulness in the rat. Psychopharmacology. 1989;97(4):436-42.

23. Monti JM, Pineyro G, Orellana C, Boussard M, Jantos $H$, Labraga P, Olivera S, Alvarino F. 5-Ht receptor agonists 1-(2,5-dimethoxy-4-iodophenyl)2-aminopropane (DOI) and 8-OH-DPAT increase wakefulness in the rat. Biog Amines. 1990;7(2):145-51.

24. Kantor S, Jakus R, Molnar E, Gyongyosi N, Toth A, Detari L, Bagdy G. Despite similar anxiolytic potential, the 5-hydroxytryptamine $2 \mathrm{C}$ receptor antagonist SB-242084 [6-chloro-5-methyl-1-[2-(2-methylpyrid-3yloxy)-pyrid-5-yl carbamoyl] indoline] and chlordiazepoxide produced 
differential effects on electroencephalogram power spectra. J Pharmacol Exp Ther. 2005;315(2):921-30.

25. Kostyalik D, Kátai Z, Vas S, Pap D, Petschner P, Molnár E, Gyertyán I, Kalmár L, Tóthfalusi L, Bagdy G. Chronic escitalopram treatment caused dissociative adaptation in serotonin (5-HT) 2 C receptor antagonistinduced effects in REM sleep, wake and theta wave activity. Exp Brain Res. 2014;232(3):935-46.

26. Silvani A, Berteotti C, Bastianini S, Lo Martire V, Mazza R, Pagotto U, Quarta C, Zoccoli G. Multiple sleep alterations in mice lacking cannabinoid type 1 receptors. Plos One. 2014;9(2):e89432.

27. Pava MJ, den Hartog CR, Blanco-Centurion C, Shiromani PJ, Woodward JJ. Endocannabinoid modulation of cortical up-states and NREM sleep. PLoS ONE. 2014;9(2):e88672.

28. Santucci V, Storme JJ, Soubrie P, LeFur G. Arousal-enhancing properties of the CB1 cannabinoid receptor antagonist sr 141716A in rats as assessed by electroencephalographic spectral and sleep-waking cycle analysis. Life Sci. 1996;58(6):!103-10.

29. Goonawardena AV, Plano A, Robinson L, Ross R, Greig I, Pertwee RG, Hampson RE, Platt B, Riedel G. Modulation of food consumption and sleep-wake cycle in mice by the neutral CB1 antagonist ABD459. Behav Pharmacol. 2015;26(3):289-303.

30. Murillo-Rodríguez E, Cabeza R, Méndez-Díaz M, Navarro L, ProspéroGarcía O. Anandamide-induced sleep is blocked by SRI41716A, a CBI receptor antagonist and by U73122, a phospholipase C inhibitor. NeuroReport. 2001;12(10):2131-6.

31. Soria-Gomez E, Marquez-Diosdado MI, Montes-Rodriguez CJ, EstradaGonzalez V, Prospero-Garcia O. Oleamide administered into the nucleus accumbens shell regulates feeding behaviour via CB1 and 5-HT2C receptors. Int J Neuropsychopharmacol. 2010;13(9):1247-54.

32. Kantor S, Jakus R, Balogh B, Benko A, Bagdy G. Increased wakefulness, motor activity and decreased theta activity after blockade of the $5-\mathrm{HT} 2 \mathrm{~B}$ receptor by the subtype-selective antagonist SB-215505. Brit J Pharmacol. 2004;142(8):1332-42.

33. Monti JM. Serotonin control of sleep-wake behavior. Sleep Med Rev. 2011:15(4):269-81.

34. Monti JM. The role of dorsal raphe nucleus serotonergic and non-serotonergic neurons, and of their receptors, in regulating waking and rapid eye movement (REM) sleep. Sleep Med Rev. 2010;14(5):319-27.

35. El Mansari M, Sakai K, Jouvet M. Unitary characteristics of presumptive cholinergic tegmental neurons during the sleep-waking cycle in freely moving cats. Exp Brain Res. 1989;76(3):519-29.

36. Monti JM, Jantos H. Effects of activation and blockade of 5-HT2A/2C receptors in the dorsal raphe nucleus on sleep and waking in the rat. Prog Neuro-Psychopharmacol. 2006;30(7):1189-95.

37. Murillo-Rodriguez $E$. The role of the $\mathrm{CB} 1$ receptor in the regulation of sleep. Prog Neuro-Psychopharmacol. 2008;32(6):1420-7.

38. Murillo-Rodriguez E, Poot-Ake A, Arias-Carrion O, Pacheco-Pantoja E, Fuente-Ortegon Ade L, Arankowsky-Sandoval G. The emerging role of the endocannabinoid system in the sleep-wake cycle modulation. Cent Nerv Syst Agents Med Chem. 2011;11(3):189-96.
39. Degroot A, Kofalvi A, Wade MR, Davis RJ, Rodrigues RJ, Rebola N, Cunha RA, Nomikos GG. CB1 receptor antagonism increases hippocampal acetylcholine release: site and mechanism of action. Mol Pharmacol. 2006;70(4):1236-45.

40. Perez-Morales M, Fajardo-Valdez A, Mendez-Diaz M, Ruiz-Contreras AE, Prospero-Garcia O. 2-Arachidonoylglycerol into the lateral hypothalamus improves reduced sleep in adult rats subjected to maternal separation. NeuroReport. 2014;25(18):1437-41.

41. Huang H, Acuna-Goycolea C, Li Y, Cheng HM, Obrietan K, van den Pol AN Cannabinoids excite hypothalamic melanin-concentrating hormone but inhibit hypocretin/orexin neurons: implications for cannabinoid actions on food intake and cognitive arousal. J Neurosci. 2007;27(18):4870-81.

42. Perez-Morales M, De La Herran-Arita AK, Mendez-Diaz M, Ruiz-Contreras AE, Drucker-Colin R, Prospero-Garcia O. 2-AG into the lateral hypothalamus increases REM sleep and cFos expression in melanin concentrating hormone neurons in rats. Pharmacol Biochem Behav. 2013;108:1-7.

43. Hassani OK, Lee MG, Jones BE. Melanin-concentrating hormone neurons discharge in a reciprocal manner to orexin neurons across the sleepwake cycle. Proc Natl Acad Sci USA. 2009;106(7):2418-22.

44. Kitka T, Adori C, Katai Z, Vas S, Molnar E, Papp RS, Toth ZE, Bagdy G. Association between the activation of $\mathrm{MCH}$ and orexin immunorective neurons and REM sleep architecture during REM rebound after a three day long REM deprivation. Neurochem Int. 2011;59(5):686-94.

45. Navarro L, Martinez-Vargas M, Murillo-Rodriguez E, Landa A, Mendez-Diaz $M$, Prospero-Garcia O. Potential role of the cannabinoid receptor CB1 in rapid eye movement sleep rebound. Neuroscience. 2003;120(3):855-9.

46. Hájos N, Freund TF. Pharmacological separation of cannabinoid sensitive receptors on hippocampal excitatory and inhibitory fibers. Neuropharmacology. 2002;43(4):503-10.

47. Ohno-Shosaku T, Tsubokawa H, Mizushima I, Yoneda N, Zimmer A, Kano M. Presynaptic cannabinoid sensitivity is a major determinant of depolarization-induced retrograde suppression at hippocampal synapses. J Neurosci. 2002:22(10):3864-72.

48. De Petrocellis L, Bisogno T, Maccarrone M, Davis JB, Finazzi-Agro A, Di Marzo V. The activity of anandamide at vanilloid VR1 receptors requires facilitated transport across the cell membrane and is limited by intracellular metabolism. J Biol Chem. 2001;276(16):12856-63.

49. Zygmunt PM, Petersson J, Andersson DA, Chuang H, Sorgard M, Di Marzo $V$, Julius D, Hogestatt ED. Vanilloid receptors on sensory nerves mediate the vasodilator action of anandamide. Nature. 1999;400(6743):452-7.

50. Savinainen JR, Saario SM, Niemi R, Jarvinen T, Laitinen JT. An optimized approach to study endocannabinoid signaling: evidence against constitutive activity of rat brain adenosine $\mathrm{A} 1$ and cannabinoid $\mathrm{CB} 1$ receptors. Br J Pharmacol. 2003;140(8):1451-9.

51. Pertwee RG. Pharmacological actions of cannabinoids. Handb Exp Pharmacol. 2005;168:1-51.

52. Luppi PH, Gervasoni D, Verret L, Goutagny R, Peyron C, Salvert D, Leger $L$, Fort P. Paradoxical (REM) sleep genesis: the switch from an aminergiccholinergic to a GABAergic-glutamatergic hypothesis. J Physiol Paris. 2006;100(5-6):271-83.

Ready to submit your research? Choose BMC and benefit from

- fast, convenient online submission

- thorough peer review by experienced researchers in your field

- rapid publication on acceptance

- support for research data, including large and complex data types

- gold Open Access which fosters wider collaboration and increased citations

- maximum visibility for your research: over $100 \mathrm{M}$ website views per year

At BMC, research is always in progress.

Learn more biomedcentral.com/submissions 